\title{
Author Spotlight: Rossella Palma
}

\section{Rossella Palma ${ }^{1}$}

Published online: 10 March 2020

(c) Springer Science+Business Media, LLC, part of Springer Nature 2020

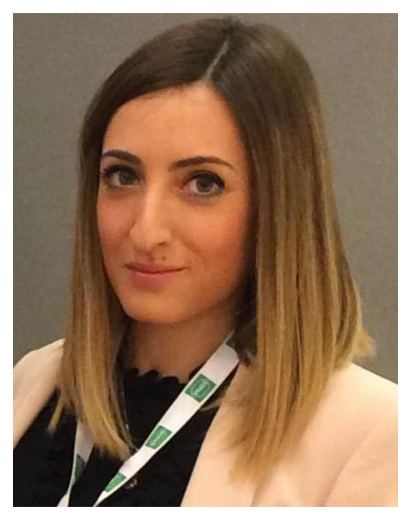

Experimental and Clinical Hepato-Gastroenterology at the "Sapienza" University of Rome. She is primarily interested in diagnostic and operative endoscopy for the treatment of gastrointestinal diseases. She plans to pursue an academic career following her $\mathrm{PhD}$ studies.

Publisher's Note Springer Nature remains neutral with regard to

Dr. Rossella Palma (rossellapalma89@gmail.com) is a genjurisdictional claims in published maps and institutional affiliations.

eral surgeon who is currently a $\mathrm{PhD}$ student in the Section of

Rossella Palma

rossellapalma89@gmail.com

1 Department of Surgical Sciences, Sapienza University

of Rome, Rome, Italy 